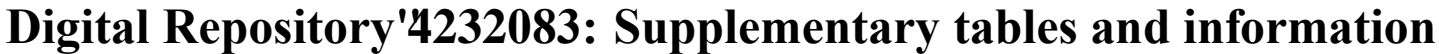

\section{"Reconciling plate kinematic and seismic estimates of lithospheric convergence in the central Indian Ocean"}

\author{
by J. M. Bull, C. DeMets, K. S. Krishna, D. J. Sanderson, and S. Merkouriev
}

\section{Overview}

This supplementary document describes the India-Capricorn-Somalia rotations that are used for the analysis presented in the accompanying Bull et al. paper and includes rotations that supersede those published in previous related studies. Updated Capricorn-Somalia and India-Somalia finite rotations and the methods used to estimate them are described first. Rotations modified for the influence of outward displacement are then presented and used as the basis for a synopsis of key kinematic results.

The estimated magnetic reversal ages are given in the tables and are from the astronomically tuned Neogene time scale of Lourens et al. (2004) for reversals younger than 7.2 Ma and older than 15.2 Ma. For reversals between these two times, we adopt more recently, astronomicallytuned reversal ages from Husing et al. (2007) and Husing (2008).

\section{Capricorn-Somalia finit rotations}

Finite rotations from DeMets et al. (2005) for twenty magnetic reversals from the present back to the old edge of Anomaly 6 (19.72 Myr) constitute the starting basis for our new CapricornSomalia rotations. Fourteen of the twenty magnetic reversals that were used by DeMets et al. (2005) to determine Capricorn-Somalia motion are correlated at the same point on the magnetic anomaly waveform as was used by Merkouriev and DeMets (2006) for their analysis of IndiaSomalia motion. Six additional reversals that were also used in both studies were correlated at slightly different points on the anomaly waveforms and therefore measure the plate motions at different times. For example, anomaly 4n. 2 was correlated at its mid-point ( $7.915 \mathrm{Myr})$ by DeMets et al. (2005), but at its old edge ( $8.132 \mathrm{Myr}$ ) by Merkouriev and DeMets (2006). We eliminated these small inconsistencies between the two studies by either increasing or decreasing the CapricornSomalia rotation angles from DeMets et al. (2005) to compensate exactly for the age difference in the magnetic reversal tie points that were used in the two studies. DR Table 1 lists the updated Capricorn-Somalia finite rotations, including these angular adjustments.

\section{Updated India-Somalia rotations}

The updated India-Somalia finite rotations (DR Table 2) are similar to, but updated from finite rotations for reversals C1n through C6no described by Merkouriev and DeMets (2006). All of the new rotations are determined from the same magnetic anomaly crossings as were used by Merkouriev and DeMets (2006). In addition, the rotations for anomalies 1 to 5Cn.3 were determined using the same fracture zone crossings as were used by Merkouriev and DeMets (2006). For Chrons 5D, 5E, and 6no, we elected to use revised sets of fracture zone crossings to estimate the new best-fitting finite rotations because two fracture zones that were selected by Merkouriev and 
DeMets for those three reversals may have been affected by slow propagating rifts that were active near the paleo-ridge axis.

For Chrons 5D and 5E, the new best-fitting rotations differ by only 0.01-0.02 angular degrees in location and 0.001-0.002 degrees in opening angle from those estimated by Merkouriev and DeMets (2006). The updated rotation for C6no however lies 0.6 angular degrees south of the Merkouriev and DeMets estimate, closer to and hence more consistent with the opening poles for Chron 5D and 5E than was previously the case. The revised set of fracture zone crossings that are used to estimate the revised best-fitting rotation for Chron 6no have lower dispersion relative to small circles around the new rotation than was previously the case. Both suggest that the updated rotation more accurately describes motion since Chron 6no than that of Merkouriev and DeMets (2006).

We also reestimated the uncertainties for all 20 India-Somalia rotations using a bootstrapping methodology that differs modestly from the bootstrapping technique used by Merkouriev and DeMets (2006). From the full pool of magnetic anomaly and fracture zone segments that we used to reconstruct each magnetic reversal, we extracted separate random samples of the fracture zone segments and paleo-spreading segments, combined all magnetic anomaly and fracture zone crossings from those randomly sampled segments, and then inverted the combined data to determine the best-fitting bootstrap rotation for that sample. After repeating this procedure one thousand times per reversal to sample the underlying data variations, we used the resulting distribution of rotations to define the rotation uncertainties.

The procedure used by Merkouriev and DeMets (2006) differs from the above procedure in one respect. Merkouriev and DeMets constructed each bootstrap data sample by repeated random sampling of the combined pool of fracture zone and paleo-spreading segments. Because some reversals included as few as three fracture zone segments, some of their bootstrap samples excluded all fracture zone data. Inversions of those samples yielded poorly determined rotations that were outliers in the distribution of bootstrap rotations. These outliers gave rise to overly large estimates of the covariances for some rotations and unduly pessimistic rotation uncertainties. Our newly estimated rotation variances are 10\%-50\% smaller than their previous estimates from Merkouriev and DeMets (2006). Both the finite rotations and covariances listed in DR Table 2 supersede those from Merkouriev and DeMets (2006).

\section{India-Capricorn-Somalia rotations corrected for outward displacement}

Outward displacement of the mid-points of magnetic reversals due to the finite width of the zone in which new seafloor acquires its magnetization biases estimates of finite rotations, as described by DeMets and Wilson (2008) and Merkouriev and DeMets (2008). We therefore corrected both the Capricorn-Somalia and India-Somalia finite rotations given in DR Tables 1 and 2 for the likely influence of outward displacement by adding to each best-fitting rotation a counter-rotation that removes the estimated outward displacement for each of these plate pairs. For the CapricornSomalia plate pair, outward displacement averages $2.0 \mathrm{~km}$ (DeMets and Wilson (2008) and was removed by adding to each Capricorn-Somalia best-fitting rotation an opposite sense small-angle rotation of $0.018^{\circ}$ about a pole located at $55.3^{\circ} \mathrm{N}, 5.3^{\circ} \mathrm{E}$. Doing so removes $2.0 \mathrm{~km}$ of net ridgenormal opening everywhere along plate boundary and yields the best corrected estimate of plate motion for this plate pair. From detailed analyses of magnetic anomaly crossings from the Carlsberg and northern Central Indian ridges, Merkouriev and DeMets (2008) and DeMets and Wilson (2008) find evidence for uniform outward displacement of $3.5 \mathrm{~km}$. We corrected for this bias by adding to each India-Somalia best-fitting rotation an opposite sense small-angle rotation of $0.032^{\circ}$ 
about a pole located at $32.7^{\circ} \mathrm{N}, 330.9^{\circ} \mathrm{E}$. This removes $3.5 \mathrm{~km}$ of net ridge-normal opening everywhere along plate boundary.

The Capricorn-Somalia and India-Somalia rotations that are corrected for outward displacement are given in DR Table 3 and are referred to hereafter as plate motion rotations since they specify plate motions free from the bias introduced by outward displacement. The rotations are corrected assuming that the magnitude of outward displacement is the same for all paleo-spreading segments. Although significant along-axis variations in outward displacement occur along other spreading centers (DeMets and Wilson 2008) and therefore add uncertainty to the corrected rotation estimates, our bootstrapping procedure implicitly accounts for such variations. The bootstrapped rotation uncertainties in DR Tables 1 and 2 are therefore appropriate for the rotations given in DR Table 3.

India-Capricorn plate motion rotations are determined from the Capricorn-Somalia and IndiaSomalia rotations (DR Table 4) and are the basis for the kinematic analysis presented in the accompanying paper. We next summarize the principal kinematic results from the newly estimated rotations.

\section{Kinematic synopsis}

DR Figures 1 and 2 summarize the primary results from the updated Capricorn-Somalia-India rotations given in DR Tables 3 and 4. The interval seafloor spreading rates for the CapricornSomalia and India-Somalia plate pairs define a period of decelerating seafloor spreading from 20 Ma to $10 \mathrm{Ma}$ (DR Fig. 1), following by a period of remarkably constant seafloor spreading from $8 \mathrm{Ma}$ to the present, as reported by Merkouriev and DeMets (2006). Differences in these and the previously reported interval rates are attributable to the systematic correction for outward displacement that is applied to all of the rotations herein and the revisions to the magnetic reversal ages that define the ages that bracket these interval rates.

Relative to the interval rates previously reported by Merkouriev and DeMets (shown by the open symbols in DR Fig. 2), the newly estimated interval rates (solid symbols in DR Fig. 2) exhibit less variation and hence more consistency from one interval to the next. The reduced scatter suggests that the updated rotations are more accurate than those presented by Merkouriev and DeMets (2006).

The India-Capricorn poles exhibit no obvious inter-dependence between their ages and their locations (upper panel of DR Fig. 2), and instead tend to scatter relatively evenly around a mean location near $3.7^{\circ} \mathrm{S}, 74.8^{\circ} \mathrm{E}$. Differences in the locations of poles of different ages are generally insignificant and are attributable to noise in the underlying India-Somalia and Capricorn-Somalia rotation estimates. The India-Capricorn pole that describes motion from the present back to $8 \mathrm{Ma}$ (labeled "4n.2" in DR Fig. 2), during a period when India-Capricorn-Somalia plate motions appear to have remained constant or nearly constant (DeMets et al. 2005; Merkouriev and DeMets 2006), is nearly coincident with the pole for the present back to $20 \mathrm{Ma}$ (labeled "6no" in DR Fig. 2). There is thus little evidence for a significant change in the direction of India-Capricorn motion since $20 \mathrm{Ma}$.

The India-Capricorn rotation angles (lower panel of DR Fig. 2) clearly indicate that the rate of angular rotation changed once and possibly twice since $20 \mathrm{Ma}$. We therefore examined the fits of two models to the rotation angles, one that postulates a single change in the angular rotation rate since $20 \mathrm{Ma}$ and the other two such changes.

For a single assumed change in the angular rotation rate, we searched systematically for the age that gives the best weighted least-squares, two-line fit to the series of rotation angles and 
their assigned reversal ages, including an angle of 0.0 degrees at $0.0 \mathrm{Ma}$. For each age that we assumed the change took place, we inverted the India-Capricorn angles from DR Table 4 to find the continuous two segment line, consisting of two slopes and one Y-intercept, that best fits the angles and their uncertainties. An inversion in which the angular rotation rate is assumed to have changed at 7.8 Ma gives the best overall fit. Repeating the above procedure with the rotation angles we derived for an assumed stationary India-Capricorn pole gives a slightly older best age of 8.0 Ma. The $68 \%(1-\sigma)$ confidence limits for these two estimates extend from 6.5 Ma to 8.7 Ma. and their $95 \%$ confidence limits extend from 5.5 Ma to 10.8 Ma.

We next sought the best model for two assumed changes in the angular rotation rate. DR Fig. 3 shows the results of a systematic search for the ages of the youngest and oldest assumed changes in motion. For each assumed age-pair shown in the figure, we inverted the India-Capricorn angles to find the three slopes and one Y-intercept that best fit the angles in a least-squares sense. Age-pairs located outside the $1-\sigma$ and $95 \%$ misfit contours (shown by the red and blue contours in the figure) are rejected at those confidence levels.

The results shown in DR Fig. 3 show that the squared misfit to the rotation angles changes significantly as a function of the age assumed for the most recent change in motion (the horizontal axis), but changes relatively little as a function of the age assumed for the earliest change in motion (the vertical axis). The change in motion at 7-8 Ma is thus well resolved by the rotation angles, whereas any change in motion before $13 \mathrm{Ma}$ is poorly resolved. The improvement in fit of the best three-slope model relative to that of the best two-slope model is not significant at the $95 \%$ confidence level (as determined from an F-ratio test) for either the best-fitting sequence of angles or the stationary pole angle sequence.

The absence of evidence in the rotation angles for three distinct stages of India-Capricorn motion since $20 \mathrm{Ma}$ can either be interpreted as evidence that no change occurred or as evidence that reconstructions of India-Somalia-Capricorn motion for times before $13 \mathrm{Ma}$ are too noisy and too widely spaced in time to reveal any such change. As we discuss in the body of our primary paper, marine seismic data indicate that India-Capricorn convergence began between 15.4 Ma and 13.9 Ma, favoring the latter of these two interpretations. 


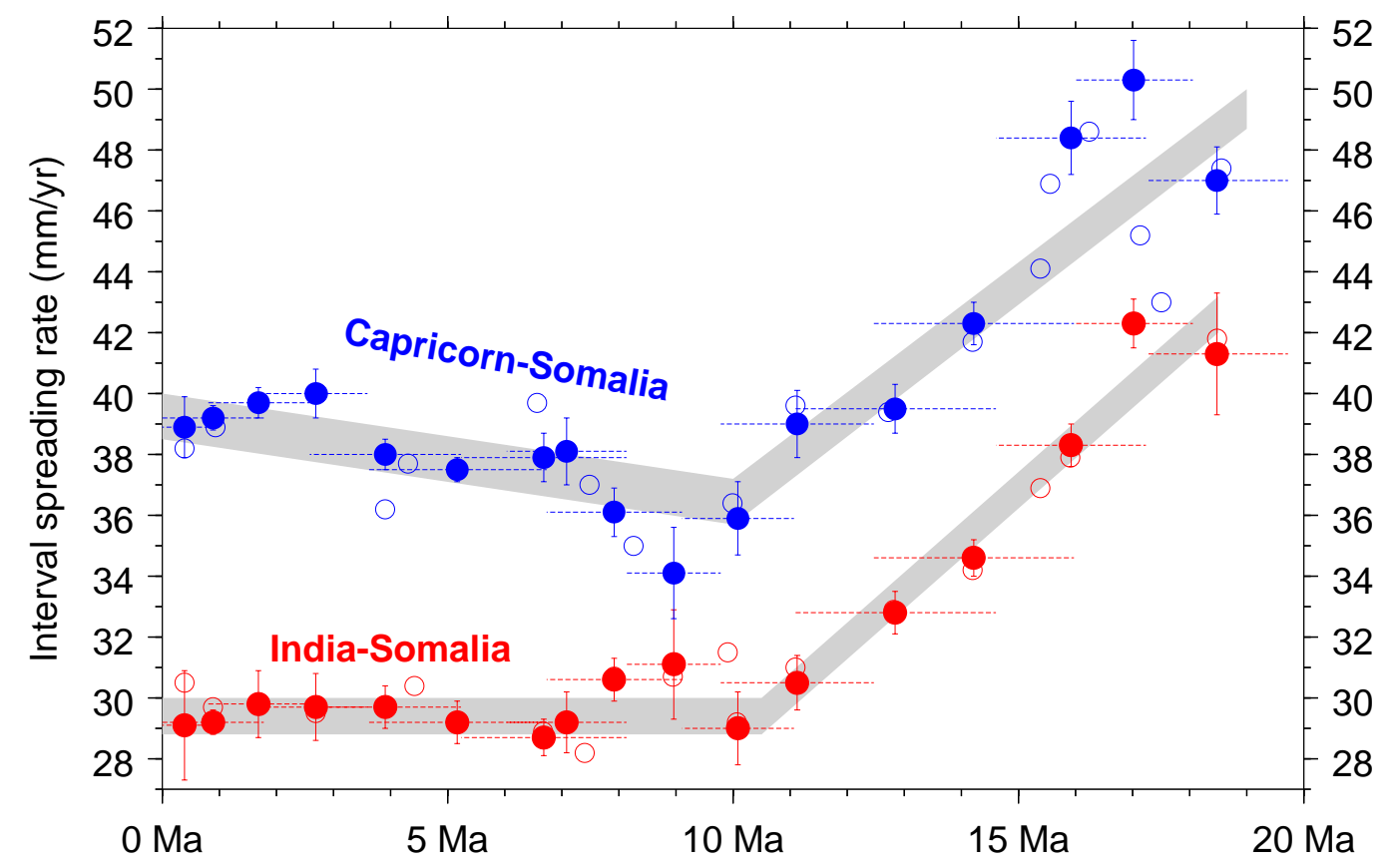

Fig.d' 5 1: India-Somalia and Capricorn-Somalia interval spreading rates, 0-20 Ma, updated for this analysis (solid symbols) and from Merkouriev and DeMets (2006) (open symbols). The updated interval rates are calculated from stage rotations determined from the rotations given in DR Table 3. Horizontal lines show the time intervals over which motion is averaged. Astronomically-tuned magnetic reversal ages are from Husing et al. (2007) for 0-7 Ma and 15.2-20 Ma and from Lourens et al. (2004) and Husing (2008) 7-15.2 Ma. Shaded bands are schematic interpretations of the spreading history. All rates are corrected for outward displacement. 


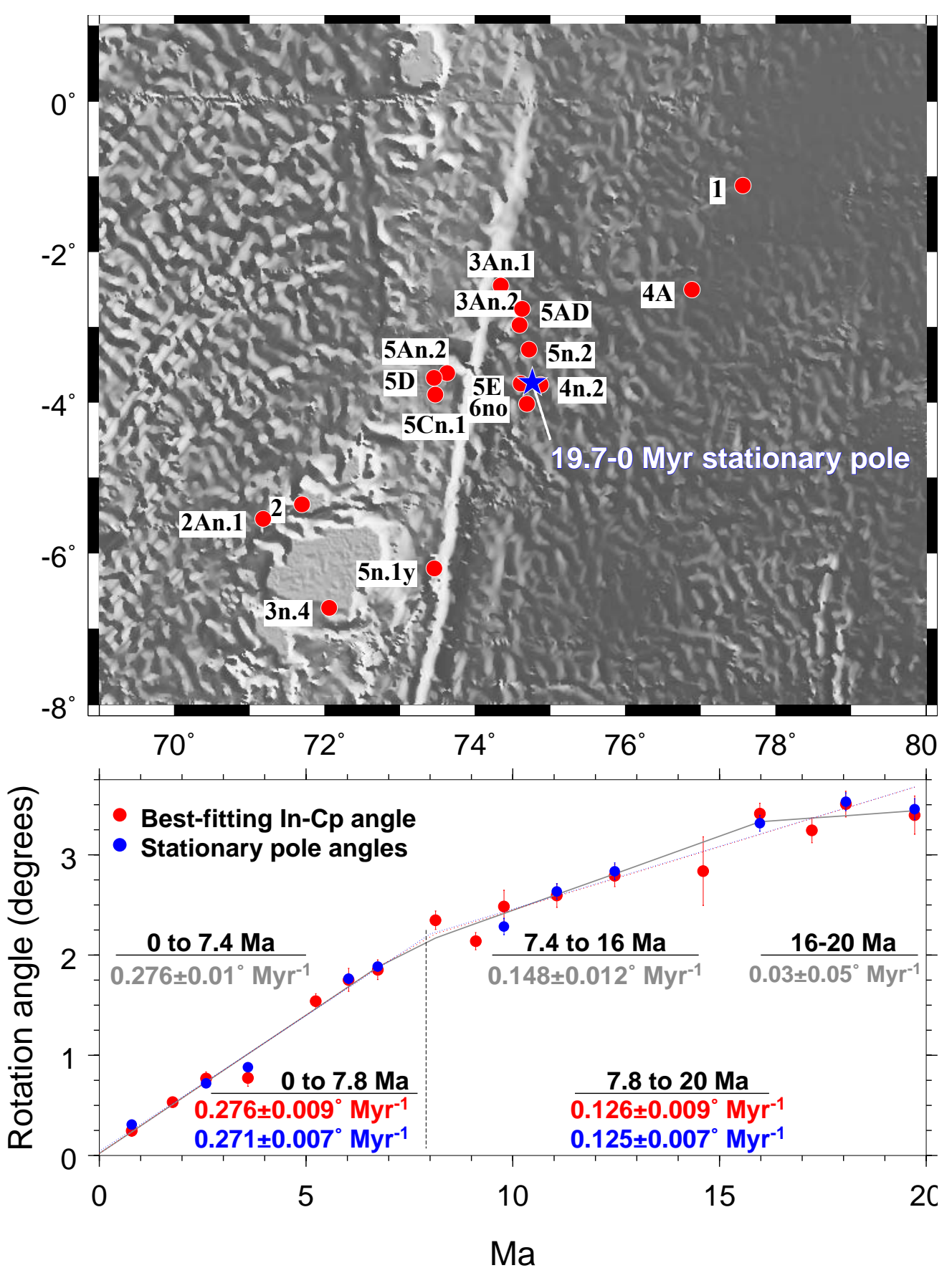

Fig. ' 5 2: India-Capricorn pole locations for anomalies 1 (0.781 Myr) to 6n (19.722 Myr), as described in text. Blue star at $3.74^{\circ} \mathrm{S}, 74.76^{\circ} \mathrm{E}$ shows the weighted mean location of the 17 best-fitting poles from DR Table 4 (red symbols). Lower - stationary-pole and best-fitting India-Capricorn rotation angles (DR Table 4). Both sets of angles clearly show that a period of more rapid motion for the past $8 \mathrm{Myr}$ was preceded by slower motion back to $16 \mathrm{Ma}$ and possibly $18 \mathrm{Ma}$. Motion before $\sim 15 \mathrm{Ma}$ may have been even slower, but cannot be resolved at statistically significant levels. Red and blue lines show continuous two-segment bestfitting lines for both sets of rotation angles. The best age $(8.0 \mathrm{Ma})$ for the change in motion was determined via a systematic search for the age that gives rise to the best two-line-segment, least-squares fit to the angles. Slope uncertainties are 1- $\sigma$. 

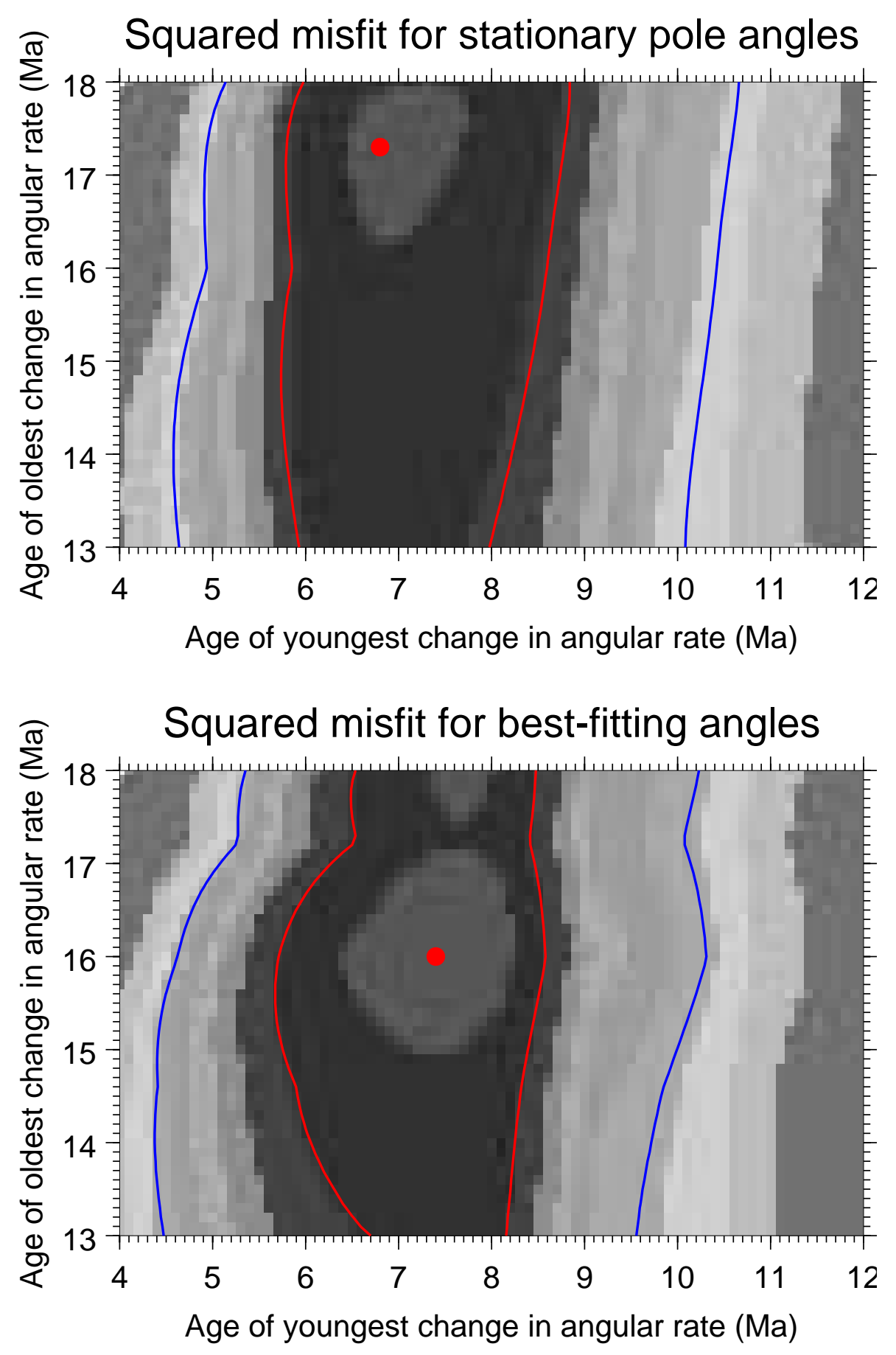

Fig.【' 5 3: Least-squares misfits to India-Capricorn rotation angles for two assumed changes in the rate of angular rotation, the youngest between 4 and $12 \mathrm{Ma}$ and the oldest between 13 and $18 \mathrm{Ma}$. Red circles show the pair of ages that yields the lowest misfit for any 3-line-segment model to the best-fitting and stationary pole rotation angle sequences from the lower panel of DR Fig. 2. Red and blue contours show the respective 1- $\sigma$ and $95 \%$ limits for the best solutions, as determined using a F-ratio test. 


\section{Papers cited}

DeMets, C., \& Wilson, D. S., 2008. Toward a minimum change model for recent plate motions: calibrating seafloor spreading rates for outward displacement, Geophys. J. Int., 174, 825-841, doi: 10.1111/j.1365-246X.2008.03836.x.

DeMets, C., Gordon, R. G., \& Royer, J.-Y., 2005. Motion between the Indian, Capricorn, and Somalian plates since $20 \mathrm{Ma}$ : implications for the timing and magnitude of distributed deformation in the equatorial Indian ocean, Geophys. J. Int., 161, 445-468.

Husing, S., 2008. Astrochronology of the Mediterranean Miocene, 171 pp., Ph. D. dissertation, Utrecht University, Utrecht, The Netherlands.

Husing, S. K., Hilgen, F. J., Abdul-Aziz, H., \& Krijgsman, W., 2007. Completing the Neogene geological time scale between 8.5 and $12.5 \mathrm{Ma}$, Earth Planet. Sci. Lett., 253, 340-358, doi:10.1016/j.epsl.2006.10.036.

Lourens, L., F. J. Hilgen, J. Laskar, N. J. Shackleton, and D. Wilson (2004), The Neogene Period, in A Geologic Time Scale 2004, ed. F. Gradstein, J. Ogg, and A. Smith, p. 909-440, Cambridge University Press, London.

Merkouriev, S., \& DeMets, C., 2006. Constraints on Indian plate motion since 20 Ma from dense Russian magnetic data: Implications for Indian plate dynamics, Geochem. Geophys. Geosyst., 7, Q02002, doi: 10.1029/2005GC001079.

Merkouriev, S., \& DeMets, C., 2008. A high-resolution model for Eurasia-North America plate kinematics since $20 \mathrm{Ma}$, Geophys. J. Int., 173, 1064-1083, doi:10.1111/j.1365246X.2008.03761.x. 
Table DR1: Finite rotations for Somalia plate onto Capricorn plate

\begin{tabular}{|c|c|c|c|c|c|c|c|c|c|c|}
\hline \multirow[t]{2}{*}{ Chron } & \multirow{2}{*}{$\begin{array}{r}\text { Age } \\
\mathrm{Ma} \\
\end{array}$} & \multirow{2}{*}{$\begin{array}{l}\text { Lat. } \\
{ }^{o} \mathrm{~N} \\
\end{array}$} & \multirow{2}{*}{$\begin{array}{l}\text { Long. } \\
{ }^{o} \mathrm{E} \\
\end{array}$} & \multirow{2}{*}{$\begin{array}{r}\Omega \\
\text { (degrees) }\end{array}$} & \multicolumn{6}{|c|}{ Covariances } \\
\hline & & & & & a & $\mathrm{b}$ & $\mathrm{c}$ & d & e & $\mathrm{f}$ \\
\hline$\overline{1}$ & 0.781 & 11.66 & 51.22 & 0.537 & 10.5 & 12.0 & -8.7 & 22.0 & -11.0 & 7.6 \\
\hline 2 & 1.778 & 10.92 & 49.18 & 1.180 & 24.1 & 19.7 & -17.8 & 30.9 & -16.4 & 13.8 \\
\hline 2An.1 & 2.581 & 11.28 & 48.71 & 1.685 & 13.4 & 16.1 & -10.0 & 27.9 & -12.8 & 7.9 \\
\hline 2An.3 & 3.596 & 13.71 & 49.62 & 2.238 & 20.6 & 17.4 & -15.8 & 29.2 & -13.8 & 12.6 \\
\hline $3 n .4$ & 5.235 & 10.49 & 49.04 & 3.400 & 30.7 & 34.9 & -23.4 & 59.8 & -27.4 & 18.8 \\
\hline 3An.1 & 6.033 & 12.64 & 48.82 & 3.687 & 54.8 & 60.9 & -41.6 & 88.9 & -48.1 & 32.7 \\
\hline $3 \mathrm{An} .2$ & 6.733 & 11.98 & 49.11 & 4.203 & 92.1 & 98.1 & -71.4 & 120.5 & -77.5 & 56.2 \\
\hline $4 n .2$ & 8.132 & 11.62 & 49.74 & 5.114 & 44.4 & 37.3 & -36.7 & 46.9 & -31.6 & 31.0 \\
\hline $4 \mathrm{~A}$ & 9.105 & 13.95 & 48.20 & 5.289 & 75.1 & 91.2 & -55.3 & 142.1 & -70.0 & 42.4 \\
\hline $5 n .1 y$ & 9.786 & 12.33 & 47.70 & 5.777 & 208.0 & 304.2 & -136.8 & 497.7 & -200.8 & 92.1 \\
\hline $5 n .2$ & 11.067 & 13.99 & 46.84 & 6.258 & 89.6 & 99.9 & -62.6 & 194.0 & -74.9 & 46.2 \\
\hline $5 \mathrm{An} .2$ & 12.464 & 14.23 & 45.81 & 6.979 & 68.7 & 85.4 & -46.9 & 202.9 & -61.9 & 34.5 \\
\hline $5 \mathrm{AD}$ & 14.607 & 16.06 & 44.47 & 7.834 & 173.4 & 298.0 & -118.5 & 588.9 & -203.4 & 85.2 \\
\hline $5 \mathrm{Bn} .2$ & 15.210 & 16.73 & 43.98 & 8.007 & 234.4 & 390.2 & -165.5 & 780.6 & -272.7 & 123.2 \\
\hline $5 \mathrm{Cn} .1$ & 15.974 & 15.14 & 44.92 & 8.926 & 77.7 & 109.6 & -53.3 & 201.6 & -75.1 & 38.8 \\
\hline $5 \mathrm{Cn} .3$ & 16.721 & 15.66 & 44.48 & 9.331 & 50.3 & 80.0 & -33.8 & 160.2 & -54.4 & 24.5 \\
\hline $5 \mathrm{D}$ & 17.235 & 16.24 & 43.92 & 9.540 & 88.6 & 157.5 & -56.7 & 314.8 & -100.6 & 38.7 \\
\hline $5 \mathrm{E}$ & 18.056 & 16.08 & 44.33 & 10.190 & 97.3 & 149.8 & -62.9 & 279.3 & -97.6 & 43.0 \\
\hline 6ny & 18.748 & 17.38 & 43.33 & 10.309 & 197.0 & 267.3 & -127.5 & 461.4 & -177.2 & 86.4 \\
\hline 6 no & 19.722 & 17.29 & 43.25 & 10.895 & 75.5 & 126.3 & -50.8 & 259.3 & -86.4 & 36.0 \\
\hline
\end{tabular}

Somalia-Capricorn finite rotations from Table 3 of DeMets et al. (2005) interpolated to magnetic isochrons consistent with Somalia-India rotations in DR Table 2. Rotation angles are anticlockwise and reconstruct the Somalia plate onto Capricorn. Covariances are Cartesian and have units of $10^{-8}$ radians $^{2}$. Elements $a, d$, and $f$ are the variances of the $\left(0^{\circ} \mathrm{N}, 0^{\circ} \mathrm{E}\right),\left(0^{\circ} \mathrm{N}, 90^{\circ} \mathrm{E}\right)$, and $90^{\circ} \mathrm{N}$ components of the rotation. The covariance matrices are reconstructed as follows:

$$
\left(\begin{array}{lll}
a & b & c \\
b & d & e \\
c & e & f
\end{array}\right)
$$


Table DR2: Finite rotations for Somalia plate onto India plate

\begin{tabular}{|c|c|c|c|c|c|c|c|c|c|c|}
\hline \multirow[t]{2}{*}{ Chron } & \multirow{2}{*}{$\begin{array}{l}\text { Age } \\
\mathrm{Ma}\end{array}$} & \multirow{2}{*}{$\begin{array}{l}\text { Lat. } \\
{ }^{o} \mathrm{~N}\end{array}$} & \multirow{2}{*}{$\begin{array}{r}\text { Long. } \\
{ }^{o} \mathrm{E}\end{array}$} & \multirow{2}{*}{$\begin{array}{r}\Omega \\
\text { (degrees) }\end{array}$} & \multicolumn{6}{|c|}{ Covariances } \\
\hline & & & & & $\mathrm{a}$ & $\mathrm{b}$ & $\mathrm{c}$ & d & $\mathrm{e}$ & $\mathrm{f}$ \\
\hline 1 & 0.781 & 19.57 & 27.97 & 0.347 & 20.0 & 34.1 & -.1 & 68.1 & 5.8 & 4.6 \\
\hline 2 & 1.778 & 21.59 & 30.83 & 0.755 & 4.3 & 6.5 & -.5 & 13.2 & 1.7 & 2.1 \\
\hline 2An.1 & 2.581 & 22.48 & 30.60 & 1.074 & 30.2 & 43.5 & -7.2 & 77.0 & -.7 & 9.4 \\
\hline 2An.3 & 3.596 & 18.70 & 34.62 & 1.642 & 46.6 & 73.8 & -6.5 & 140.7 & 5.4 & 13.0 \\
\hline $3 n .1$ & 4.187 & 22.11 & 28.45 & 1.740 & 44.9 & 72.0 & -4.1 & 132.2 & 3.4 & 8.5 \\
\hline $3 n .4$ & 5.235 & 22.05 & 31.64 & 2.181 & 23.0 & 35.9 & -4.1 & 68.0 & 0.7 & 6.0 \\
\hline 3An.1 & 6.033 & 22.89 & 28.11 & 2.333 & 74.3 & 117.5 & -20.2 & 224.6 & -7.7 & 23.4 \\
\hline 3An.2 & 6.733 & 21.32 & 30.92 & 2.748 & 25.9 & 48.0 & -1.3 & 95.5 & 2.2 & 4.2 \\
\hline 4n.1y & 7.554 & 22.61 & 30.57 & 2.982 & 62.7 & 120.8 & -6.4 & 264.7 & 9.8 & 17.8 \\
\hline $4 n .2$ & 8.132 & 22.01 & 30.79 & 3.281 & 50.6 & 82.3 & -14.5 & 153.8 & -10.7 & 14.1 \\
\hline $4 \mathrm{r} .2$ & 8.771 & 22.48 & 30.77 & 3.489 & 48.7 & 64.4 & -17.7 & 133.8 & 8.6 & 29.4 \\
\hline $4 \mathrm{~A}$ & 9.105 & 22.59 & 30.78 & 3.685 & 15.9 & 18.4 & -7.7 & 37.8 & 2.8 & 12.5 \\
\hline $5 \mathrm{n} .1 \mathrm{y}$ & 9.786 & 23.59 & 30.49 & 3.890 & 34.0 & 51.2 & -4.2 & 100.1 & 10.8 & 14.8 \\
\hline $5 n .2$ & 11.067 & 23.62 & 29.30 & 4.311 & 49.3 & 75.5 & -4.3 & 156.0 & 14.3 & 13.3 \\
\hline 5An.2 & 12.464 & 23.80 & 29.26 & 4.879 & 38.6 & 56.2 & -8.6 & 101.3 & 1.4 & 13.4 \\
\hline $5 \mathrm{AD}$ & 14.607 & 24.60 & 29.14 & 5.760 & 33.8 & 66.2 & 1.2 & 136.6 & 5.0 & 2.2 \\
\hline $5 \mathrm{Cn} .1$ & 15.974 & 24.80 & 29.30 & 6.399 & 15.3 & 24.5 & -3.1 & 55.6 & 1.6 & 4.3 \\
\hline $5 \mathrm{D}$ & 17.235 & 24.83 & 30.29 & 7.149 & 21.5 & 32.0 & -4.0 & 63.3 & 2.5 & 6.0 \\
\hline $5 \mathrm{E}$ & 18.056 & 24.77 & 30.27 & 7.637 & 31.6 & 60.6 & -.2 & 128.2 & 5.1 & 3.4 \\
\hline 6no & 19.722 & 25.41 & 30.60 & 8.469 & 376.8 & 365.7 & -197.7 & 551.9 & -80.4 & 172.7 \\
\hline
\end{tabular}

Somalia-India rotations modified from Merkouriev and DeMets (2006) as described in the text. Rotation angles are anti-clockwise and reconstruct the Somalia plate onto India. Information about the covariances is given in the footnotes to DR Table 1. 
Table DR3: Rotations corrected for outward displacement

\begin{tabular}{|c|c|c|c|c|c|c|c|}
\hline \multirow[t]{2}{*}{$\overline{\text { Chron }}$} & \multirow{2}{*}{$\begin{array}{l}\text { Age } \\
(\mathrm{Ma})\end{array}$} & \multicolumn{3}{|c|}{ Somalia-Capricorn } & \multicolumn{3}{|c|}{ Somalia-India } \\
\hline & & $\begin{array}{l}\text { Lat. } \\
{ }^{o} \mathrm{~N}\end{array}$ & $\begin{array}{r}\text { Long. } \\
{ }^{o} \mathrm{E}\end{array}$ & $\begin{array}{r}\Omega \\
\text { (degrees) }\end{array}$ & $\begin{array}{l}\text { Lat. } \\
{ }^{o} \mathrm{~N}\end{array}$ & $\begin{array}{r}\text { Long. } \\
{ }^{o} \mathrm{E}\end{array}$ & $\begin{array}{r}\text { Omega } \\
\text { (degrees) }\end{array}$ \\
\hline 1 & 0.781 & 10.24 & 52.04 & 0.527 & 17.55 & 32.12 & .328 \\
\hline 2 & 1.778 & 10.28 & 49.54 & 1.170 & 20.72 & 32.78 & 0.737 \\
\hline 2An.1 & 2.581 & 10.84 & 48.97 & 1.675 & 21.90 & 31.96 & 1.055 \\
\hline 2An.3 & 3.596 & 13.39 & 49.81 & 2.228 & 18.26 & 35.53 & 1.626 \\
\hline $3 n .4$ & 5.235 & 10.27 & 49.16 & 3.390 & 21.76 & 32.31 & 2.163 \\
\hline 3An.1 & 6.033 & 12.45 & 48.94 & 3.676 & 22.65 & 28.73 & 2.313 \\
\hline 3An.2 & 6.733 & 11.81 & 49.21 & 4.193 & 21.09 & 31.45 & 2.730 \\
\hline $4 n .2$ & 8.132 & 11.48 & 49.82 & 5.104 & 21.83 & 31.24 & 3.262 \\
\hline $4 \mathrm{~A}$ & 9.105 & 13.81 & 48.29 & 5.279 & 22.44 & 31.18 & 3.666 \\
\hline $5 n .1 y$ & 9.786 & 12.21 & 47.78 & 5.767 & 23.45 & 30.87 & 3.870 \\
\hline $5 n .2$ & 11.067 & 13.88 & 46.91 & 6.247 & 23.50 & 29.64 & 4.292 \\
\hline 5 An. 2 & 12.464 & 14.13 & 45.87 & 6.967 & 23.69 & 29.56 & 4.859 \\
\hline $5 \mathrm{AD}$ & 14.607 & 15.98 & 44.53 & 7.823 & 24.51 & 29.40 & 5.740 \\
\hline $5 \mathrm{Cn} .1$ & 15.974 & 15.06 & 44.97 & 8.915 & 24.72 & 29.54 & 6.379 \\
\hline $5 \mathrm{D}$ & 17.235 & 16.17 & 43.97 & 9.528 & 24.76 & 30.50 & 7.130 \\
\hline $5 \mathrm{E}$ & 18.056 & 16.01 & 44.37 & 10.178 & 24.71 & 30.47 & 7.617 \\
\hline 6 no & 19.722 & 17.23 & 43.29 & 10.883 & 25.35 & 30.78 & 8.450 \\
\hline
\end{tabular}

Somalia-Capricorn and Somalia-India rotations corrected for outward displacement. Rotation angles are anti-clockwise and reconstruct the Somalia plate onto the India and Capricorn plates. Somalia-Capricorn finite rotations in DR Table 1 have been perturbed by a clockwise rotation of $0.018^{\circ}$ about a pole located at $\Omega=55.3^{\circ} \mathrm{N}, 5.3^{\circ} \mathrm{E}$ to correct for the influence of $2 \mathrm{~km}$ of outward displacement along the plate boundary. Somalia-India finite rotations from DR Table 2 have been perturbed by a clockwise rotation of $0.032^{\circ}$ about a pole located at $\Omega=32.7^{\circ} \mathrm{N}, 330.9^{\circ} \mathrm{E}$ to correct for $3.5 \mathrm{~km}$ of outward displacement along the Carlsberg Ridge. The rotation uncertainties are given in DR Tables 1 and 2. 
Table DR4: Capricorn-India plate motion rotations

\begin{tabular}{|c|c|c|c|c|c|c|c|c|c|c|}
\hline \multirow[t]{2}{*}{ Chron } & \multirow{2}{*}{$\begin{array}{r}\text { Age } \\
\text { Ma }\end{array}$} & \multirow{2}{*}{$\begin{array}{l}\text { Lat. } \\
{ }^{o} \mathrm{~N}\end{array}$} & \multirow{2}{*}{$\begin{array}{l}\text { Long. } \\
{ }^{o} \mathrm{E}\end{array}$} & \multirow{2}{*}{$\begin{array}{r}\Omega \\
\text { (degrees) }\end{array}$} & \multicolumn{6}{|c|}{ Covariances } \\
\hline & & & & & $\mathrm{a}$ & $\mathrm{b}$ & $\mathrm{c}$ & $\mathrm{d}$ & $\mathrm{e}$ & f \\
\hline$\overline{1}$ & 0.781 & 1.12 & 77.56 & -.248 & 30.2 & 46.1 & -8.7 & 90.4 & -5.1 & 12.3 \\
\hline 2 & 1.778 & 5.36 & 71.70 & -.533 & 27.7 & 26.2 & -18.1 & 44.7 & -14.8 & 16.0 \\
\hline 2An.1 & 2.581 & 5.55 & 71.18 & -.768 & 42.2 & 59.3 & -16.5 & 106.1 & -13.1 & 17.6 \\
\hline 2An.3 & 3.596 & 1.02 & 79.64 & -.772 & 64.3 & 90.5 & -21.1 & 172.0 & -7.6 & 26.5 \\
\hline $3 n .4$ & 5.235 & 6.73 & 72.06 & -1.541 & 49.8 & 69.8 & -25.6 & 131.4 & -26.0 & 25.1 \\
\hline 3An.1 & 6.033 & 2.45 & 74.34 & -1.752 & 118.5 & 175.5 & -56.8 & 323.1 & -54.1 & 57.2 \\
\hline $3 A n .2$ & 6.733 & 2.97 & 74.59 & -1.854 & 106.0 & 143.6 & -67.4 & 227.5 & -76.6 & 60.9 \\
\hline $4 n .2$ & 8.132 & 3.77 & 74.87 & -2.348 & 84.2 & 117.5 & -46.7 & 209.8 & -42.1 & 46.9 \\
\hline $4 \mathrm{~A}$ & 9.105 & 2.51 & 76.88 & 139 & 78.2 & 106.4 & -57.0 & 192.8 & -67.9 & 54.9 \\
\hline $5 \mathrm{n} .1 \mathrm{y}$ & 9.786 & 6.20 & 73.46 & -2.486 & 207.7 & 342.1 & -122.5 & 637.7 & -184.2 & 101.2 \\
\hline $5 n .2$ & 11.067 & 3.30 & 74.72 & -2.594 & 120.1 & 169.5 & -58.3 & 367.4 & -53.9 & 60.9 \\
\hline 5An.2 & 12.464 & 3.61 & 73.63 & -2.793 & 90.4 & 134.6 & -46.7 & 321.7 & -51.8 & 47.3 \\
\hline $5 \mathrm{AD}$ & 14.607 & 2.76 & 74.62 & -2.837 & 162.0 & 335.0 & -87.0 & 786.8 & -170.9 & 71.4 \\
\hline $5 \mathrm{Cn} .1$ & 15.974 & 3.90 & 73.47 & -3.411 & 71.8 & 124.4 & -44.2 & 282.5 & -64.9 & 39.0 \\
\hline $5 \mathrm{D}$ & 17.235 & 3.68 & 73.46 & -3.245 & 81.9 & 171.4 & -41.9 & 415.5 & -79.3 & 35.5 \\
\hline $5 \mathrm{E}$ & 18.056 & 3.75 & 74.61 & -3.507 & 96.5 & 191.4 & -42.7 & 447.7 & -72.0 & 38.8 \\
\hline 6 no & 19.722 & 4.02 & 74.69 & -3.395 & 341.7 & 475.3 & -197.5 & 908.9 & -154.4 & 221.5 \\
\hline
\end{tabular}

Capricorn-India rotations determined from rotations in DR Table 3 and rotation covariances in DR Tables 1 and 2. Positive rotation angles are anti-clockwise and reconstruct the Capricorn plate onto India. Frame of reference is the India plate. Information about the covariances is given in the footnotes to DR Table 1. 